\title{
A Labour of Love: The Emotional Work Associated with Parenting Children on the Autistic Spectrum
}

\author{
Jonathan Beckett \\ University of Wolverhampton \\ Wolverhampton, England
}

\begin{abstract}
This project focuses on the emotional impact, inclusive of fatigue, stress and other inter-related symptoms, associated with the parenting of children on the autistic spectrum. As a theretical overlay, the research applies Hochschild's (1983) schema of 'emotional work' to the types of care parenting those with autistic spectrum disorders may create. This qualitative research applies inductive thematic analysis, grounded in human experience, focusing upon biographical, narrative data obtained through the interviwing of two parents, of whom have children with autism spectrum disorders (pseudonyms are employed throughout the narrative). Through interviewing the participants, rich thick descriptive data wasmobtained, providing a greater conceptual clarity of how parenting children with austism spectrum disorders / conditions affects. Moreover, the scope of this work has primarily illumined the participants' feelings and, thus, highlighted the psychological impact of attending to their children's needs; descriptions of how autism has drained emotional supplies of energy, with demands of rigidity of cognition, lack of social and emotional awareness and articulating with difficulty. This research paints a poignant picture of life thereof, as lived by the participating parents, offering some generalisability beyond the data elicited from this work. Against this background, the project examines the implications of, and possible context for the implementation of educational and social work intervention and practice. This includes: enhanced awareness of the implications of the triad of difficulties assciated with the autistic spectrum (social communication, social imagination and social interaction), release of carers for respite breaks and highlights the need for further training and research into the pscyhological impact of the emotional labour of love in parenting those with autism spectrum disorders. Finally, strategies are offered which aim towards the reduction of sensory overload and the creation of a calming environment, which individual needs can be understood with greater clarity for the benfit of teachers, social workers, parents and others involved the the lives of those with autistic spectrum disorders.
\end{abstract}


Keywords: autism spectrum disorder; emotional work; parenting; qualitative research; biographical research.

\section{Introduction}

This work critically assesses the potential for the parents of children with Autism Spectrum Disorders (ASDs) or Autism Spectrum Conditions (ASCs) to experience emotional impact. For the purposes of this paper, the term ASD is applied, so as to recognise the historical perspective of the disorder; however, it also acknowledges that some practitioners and individuals are of the persuasion that, as a condition, ASD should be termed ASC.

The notion of "emotional work" (Hochschild, 1983) is used as a descriptor for the feelings of emotional expressions involved in the unpaid work of parenting / caring for children with specific needs, in this case: an Autism Spectrum Disorder (ASD). Hochschild (1983) referred to the presentation of self by deep acting, putting on a front, disguising the inner feelings in an attempt to align behaviours to norms and expectations.

This project draws on data from two dyads - parents who have sons formally diagnosed with ASD. In so doing, the work addresses their perceptions of how they manage the parental responsibilities and requirements of looking after a child with ASD.

To provide context, a vingette is given: Vicky, a single mother (due a marital breakup), is the carer for her autistic son, John. She is also a full-time teacher. At the time of the study, she worked as the Head of Department at a local secondary school. Although John was initially sent to a mainstream school, it became apparent that his having ASD was causing problems, and consequently Vicky and her husband, Philip,moved John to a specialist school. Jones (2002) notes that "all children with ASDs will experience some difficulties in learning via the traditional methods used in schools"(p. 9). Vicky described how she struggled to cope emotionally, physically and practically with the challenges of raising John. This research explores Vicky's perceptions of her experience of motherhood, focusing on the emotional work involved caring for her son.

The second particiapnt, given the pseudonym Sarah who spoke about her experinces of caring for her autistic son, assigned the pseudonym, Max. Max was 11 years old at the time of this research, he was struggling to cope with the challenges of mainstream education, in particular, the difficulties understanding the routines associated with social interactions, lesson changes, expectations in school and sudden flux in daily routines. At the time of her interview, Sarah was in the process of deciding upon the most suitable educational path for Max, as he transitioned from primary to secondary school. For Sarah, the experience of raising Max was both rewarding and challenging. Specifically, her account illuminates issues surrounding the suitability of the mainstream educational system for children with ASD. 


\section{Literature Review}

First, formally recognised and reported in the 1940s by Leo Kanner (Kanner, 1943), the nebulous nature of ASDs, more greatly acknowledged after the 1970s and onwards, relates to 'a wider spectrum of autistic disorders' (Wing, 2003, p. 22), meaning the disorder or condition exists on a continuum. MacKenzie (2008) writes: 'Autism is referred to as a 'spectrum' because the amount or severity of each of the major characteristics varies considerably from individual to individual' (p. 20). By nature, the condition is complex in its manifestations and varying in its appearances, affecting the diagnosis and recognition of ASD and the subsequent aetiology of the condition (Jordan, 2013). A further complexity that exists it that contemporaneous there is no medical test to diagnose autism 'rather a diagnosis is made through the observation of the child and an interview process with the parent...' (Hamlin, 2015:26). This requires skilful judgement and a practitioner with specific knowledge of the condition, however, the process is subjective, evident in the variation of aetiology.

Although it is important not to primarily associate an unequivocal understanding of Autism Spectrum Disorders (ASDs) within a deficit model, ASD is, however, characterised by a triad of difficulties. These are well documented and established, including rigidity of thinking, challenging behaviour, and social-communication problems (Tarbox et al., 2014). Rigid thought processes can lead to individuals becoming stressed and exhibiting challenging behaviours, which can have an adverse emotional impact upon the carers. Yau (2012) notes: 'Children with autism are often very focused on their own agenda...' (p. 24). This fixation upon a singular mental position can be seen as a sign of inflexibility, associated with the condition. Moreover, Karim et al. (2014) write that the characteristics of lack of flexible thinking include literal thinking, obsessive thinking, poor social imagination and requirements for 'sameness and routines' (p. 29).

'Mind-blindness', a term first used by Simon Baron-Cohen (1995), referring to those with ASD who possess a fixed, non-permeable view and can therefore find it difficult to accept the state of flux, adjust to situations as they occur (BaronCohen, 1995). Individuals may find managing their social identity problematic as they are unlikely to be able to respond to social cues from non-verbal behaviour, such as facial expressions, the tone of voice, the look in the eyes, and posture (Boyd, 2004). As a result of social-communication difficulties, interacting and expressing feelings can be problematic. Thus, 'inappropriate' behaviours such as outbursts and tantrums may be exhibited, as well as cyclical 'meltdowns' (Colvin and Sheehan, 2012: passim) and the link between this and parental stress becomes an iterative process.

Against this backdrop, innovative and original-insightful research into the prevailing features of ASD and potential emotional impact of parenting is needful as the current limited body of academic research, informing practice, appears limited. Dabrowska and Pisula (2010) do underline the paternal stress associated in meeting the holistic needs of those with ASD. In addition, Carr et al. (2016) argue that the tension of parenting children with ASD has a significant psychological and emotional impact upon the mental wellbeing of the individual. However, little innovative qualitative research has been conducted 
that analyses the emotional impact of parenting a child with ASD. Thus, the nature of research is therefore appropriate and timely. A critical appraisal may also highlight that some of the other features of ASD play a part in the emotional impact of managing the condition upon carers. For example, the correlation or otherwise of literal interpretations of language, heightened sensory sensitivity (Hoopmann, 2015), among other characteristics, with carers' emotional response, is relatively unexplored. Similarly, the research will apply the term 'emotional work' (Hochschild, 1983) as a descriptor of the emotional impact involved in looking after a child with specific needs arising from a diagnosis of ASD. This is significant as an understanding of the psychological implications for those affected by caring for those with ASD is, at present underdeveloped, and such holistic insights could benefit multiple disciplines.

\section{Research Aims}

The aims of this research were:

- To explore the parents' perceptions of their experience of raising a child with Autism Spectrum Disorder (ASD).

- To explore the potential emotional work involved in parenting a child with Autism Spectrum Disorder (ASD) for the benefit of offering original and unique insights for other parents, practitioners such as, teachers and social workers.

\section{Methodology}

Selfhood plays an important place in the tenets of this research from defining, shaping and drawing deductions. Letherby and Bywaters (2007) argue that the researcher should 'locate' themselves within the 'research process' (p. 39). In this work, the researcher saw himself as a learner in the process, asking the participants, what is life like for them. The implications of power-relationships were lessened on respect of the presentation of self as an interested 'learner' in their unique insights into their lives lived. This provided ease for the participants and the likelihood of them 'opening up' the data being an honest reflection of their feelings. Use of reflexivity is acknowledged throughout the research, locating how my own experiences intersected with those the participants shared and how this impacted upon the in the way the researcher listened and built the case for the emerging themes (Merriam and Grenier, 2019). Moreover, verisimilitude necessitates grounded deductions explicitly based upon what the participant's state in the research. Thus, validity was sought by descriptive accuracy; notes were taken as questions were asked and the interviewees were invited to ratify these prior to leaving the room. In so doing, the work sought to be transparent and promote dependable, valid results, as far as being impartial as possible, which if another were to research, with integrity, in a similar way, would achieve similar reliable outcomes (Creswell and Creswell, 2018).

The two participants who contributed to this project, Sarah and Vicky, were sourced by the researcher via a contact within another institution. Both participants were given information prior to their agreement, outlining the aims of the project and some background information about the insitution and the 
research methods proposed in this study. Additionally, the information pack highlighted the way in which the data would be stored securely, on a coded data stick and password protected computer, and analysed - thematically coded and extrapolations made thereby. After the packs were read and questions asked, each person was asked, without coersion, if they wished to participate and given the option of withdrawal from the study at any point, without needing a reason. Formal written consent was given and an ethics panel met to ratify my research proposal for this work, which conforms to ethical standards, for the implemenation and subsequent analysis of research. Ethical conduct was, as Kara (2018) notes, underpinning every stage of the research, from the initial design, to relationships with interviewees, the data collection, analysis and dissemination. Significantly altered sobriquets and pseudonyms were given to people and places to prevent attribution of data and reduce the risks of harm.

Interviewing was employed as a means to ascertaining Vicky's experience of raising John (including both her perception and experience of disruptive behaviours as exhibited thereof). In the interview context, she was provided with the opportunity to both discuss in general, and identify specific situational examples pertaining to the experience of raising a child with ASD. Sarah, the second participant, also participated in interviews, thus providing insights into the challenges and rewards inherent to the experience of caring for her son, Max. In terms of the benefits of the interview, both contextual meaning and the communicative expression of thoughts as relevant to (qualitatively important) key events can be attained through the creation of an environment in which participants are encouraged to tell personal stories (Atkinson, 1998). A semistructured approach to interviews was employed, thus allowing both the researcher and the interviewee the opportunity to exchange their thought and opinions in response to the pre-determined questions. The questions were generally open-ended (i.e. when did you first suspect that John had ASD? Tell me about your experiences when John was first diagnosed with ASD? What happened at home / school? How did (or does) John impact your life?).

\section{Data Analysis}

The interviews were analysed using applied thematic analysis: 'Thematic coding is a form of analytical coding which involves the search for thematic patterns in the coded data...' (Wilson, 2010, p. 32). This involved using content analysis to create robust codes of the interview transcripts, with Guest et al.'s (2012) model for thematic codification being the approach employed thereof. This included analying the salient points raised by Sarah and Vicky, using a computersied system, similar to a qualitative version of NVivo software, which helped categorise the statements into pertient themes with specific headings. These headings helped to produce further sub-headings which analysed the psychological, and other, impacts upon Sarah and Vicky; thus, applying Corbin and Stauss's (2015) notion of building up a theory. It was of significance that transference of the researcher's agenga and experince did not occur, which would have meant biased reflections of the data. Awareness of reflexivity in this type of social research, as well as acknowledging the positioning of oneself within the project, and the potential impact of this was aided by reflecting judiciously upon the interpretations of data with a colleague, unassociated with 
the project, acting as a 'critical friend' (Shacklock and Smyth, 2002, p. 48) seeking to limit the impact of bias. Equally, both participants were invited to verify the initial analysis and extrapolations, which was cross-referenced against my notes, to ensure the transparency, reliability and validity of the data.

\section{Analysis and Discussion}

The interviews sought to ascertain how and when the participants first recognised the behavioural signs of ASD, how this led to diagnosis, and the following events thereof. Vicky identified that she had first noticed the potential indicators of ASD when her child was 18 months old. In contrast, Sarah stated that her knowledge of ASD was limited, and that she had little understanding of Max's needs reakting to ASD until he was 6 years old. Vicky noted that her heightened awareness of special needs and, specifically autism, was due to her work as a senior school teacher. Sarah took the view that her superficial awareness of ASD, at the time, may have resulted from the fact that she was not employed within the education system, and thus lacked any exposure to, and training regarding both the requirements and symptoms of special needs and autistic children. For Vicky, the traits that demonstrated John was autistic were his inflexibility, inadaptability, his wheat intolerance and a defined rigidity in his thinking, all of which amplified in intensity during his early years. BaronCohen (2008) highlights "sensory systemising" (p. 67) as a common trait, which includes behaviours such as wearing the same clothes every day and insisting on the same foods each day. Vicky explained that, when she went to the supermarket with John, she had to purchase certain items, otherwise he would have a "temper tantrum." When Sarah was interviewed, she stated that "unless Max had certain things in a particular way, he would become restless and irritable or tearful."

Sarah explained that, when at school, Max struggled to cope with the demands of lesson changes, as well as the spontaneous events and irregularities that can occur within a school environment: "He just couldn't cope with all the noises, the hustle and bustle and timetables and locating his way around the school and all the people - it was just too daunting." Vicky also noted that the mainstream educative system was not appropriate for John, specifically as differentiation is often established thereof through learning outcomes (as opposed to specialist intervention and diagnosis). Roth and Barson (2010) state that: "with a spectrum such as autism a 'one size fits all' approach to education provision is not feasible" (p. 226). The main diffciluty both John and Max had was they struggled to management their emotions behaviour, particularly when forced to adapt to changes to the structure of the school day. Hawkes (2013) states that "they find sudden changes of routine or changes to the environment difficult to cope with" (p. 45).

Resistance to changes in routine, inflexibility of thought, and behaviour management issues were identified by Vicky and Sarah both as causes of emotional strain. Vicky felt that it was not in the best interests of her son to send him to a mainstream school, despite his needs being recognised in an Education and Health Care Plan (EHCP) (replacing former 'Statements' of Special 
Educational Need and Section 139 of Learning Difficulty Assessments (LDA); a plan outlining the individuals specific educational and health issues and how care may be implemented, applicable from birth to 25 years old, (Nettleton and Friel, 2017)). Vicky was further concerned that the day-to-day experience of classroom routines might be "too much for him," creating the potential for the manifestation of behavioural difficulties. Vicky said she had experineced "... a crisis of conscience over what to do" and she felt "torn" by having to decide between seeking out a specialist educational provideror enrolling her son in the mainstream education system. Her son's EHCP was, in her view, a superfluous "tick box" exercise, intended to retain school funding and (to an extent) ensure accountability in the provision of care.

One of the reasons for the EHCP was that John had problems with language development. This became apparent when hr did not understand spoken language. John's language problems made communication difficult, causing feelings of frustration and the emergence of extremeties of behavioural difficulties. Some of these problems were overcome when John started private lessons with a speech and language therapist, whereas some of the them appeared to Viicky as concomitant, idicative features of what she later understood more fully as ASD. Within a short space of time, John was able to communicate his feelings and needs through drawings. Attaining the ability to express himself impacted positively upon both John and the family as a whole. Vicky stated that: "he was less locked into his little world." However, along with understanding the challenges and frustrations faced by John, understanding Vicky's perspective, specifically in terms of the psychological impact of caring for a child with ASD, is important to ensuring the effectiveness ofASD educational and social work, especially with regard to psychological assessment, curricula and intervention (Leaf, 2017).

Vicky acknowledged the overhaul of caring for John had gradually accumulated, from first suspecting that there might be a problem, to his diagnosis, and then having to live with and manage his ASD on a daily basis. These factors had culminated in a range of emotions, from explosion to acceptation of the diagnosis, however, what appeared clear was her fight for the rights of her son. Moreover, Bierens (2010) cites an example of a parent who fought a great fight both internally, with inner emotions, and extrernally, with the education system, seeking to access specialist provision: "It's hard. You just have to keep fighting as you go along" (p. 39). Vicky's emotions thereof were mixed. She noted that she was, at times, clinically depressed. However, alongside such long-term negative effects, she did experience a sense of relief when her initial diagnosis was confirmed. She stated that the period after the ASD diagnosis was difficult, but she took some comfort from the fact that she now had a name or a label for why John was behaving in an abnormal manner. Sarah also experienced a mixed emotions upon max's diagnosis, feeling both relief (in terms of identifying the problem) and trepidation (in terms of what the future would hold for both herself, as the parent, and her son, for whom she could perceive few life-prospects). 
Vicky explained that the mental health issues she had experienced (specifically, her depression) were, in her view, a substantial psychological reaction to the ASD diagnosis and the emotional strain of raising John. She argued that, although some people are inherently more susceptible to depression than others, having to look after John, especially when he was such "hard work," was emotionally tiring and had affected her psychological wellbeing. Vicky reported experiences including sleep deprivation on account of her diagnosis of depression: "I've been up caring for him... I've been up worrying for him and how he will cope and, actually, how I will continue to cope, as I don't feel as though I am." Vicky apppears to be acting, performing an emotional script, as an attempt to align her behaviour with what Hochschild (1983) saw as the impact of iterative emotional work. Hochschild (1983) calls these scripts for emotions feeling rules: "Feeling rules are what guide emotion work by establishing the sense of entitlement or obligation that governs emotional exchanges" (p. 56). These feeling expectations are evolved social expectations of determining factors such as: what is to be felt, when to feel it, where to feel it, how long to feel it, and how strong our emotions can be. Vicky seems to possess a paradigm of feeling as though she cannot admit to being overwhelmed by stress, as this is not acceptable within society.

Although Sarah did not report that she had experienced mental health problems, she did note that she had an iterative, cyclical process of internal, stress, worry and release feelings, a significant amount of the time. She also stated that, for the sake of her psychological wellbeing, she had to take periodic weekend breaks away from Max. Even though such respite breaks would leave her feeling refreshed and more able to cope with Max's indicative behaviours of what she believed to be: "the by-product of ASD", she commented: "I feel guilty that I wanted time away." She explained that this type of guilt - cycle could make her anxious and affect the quality of her sleep. Again, the interface of emotional work and appearing to manage her emotions appears in these sentements, a key priciple of Hochschild's (1983) research. Equally, Drew and Green (2016) note how being a parent of a child with Speical Educational Needs (SEN) can adversely impact upon quality of daily living, quality of sleep at night and can lead to poor mental health and wellbeing, specifically, with enhanced levels of stress, anxiety and suseptibility to depression. The nature of her anxiety was such that Vicky could not sleep due to the stress of perpetually having to look after John. This according to the General Practitioner (GP) had been a significant factor in forming depression, which, in turn,detrimentally impacted the quality of her sleep, thus creating a cyclical sleep deprivation and anxiety circuit. Consequently, her depression deepened and became entrenched. Cheney (2008) wrote in her autobiography: "I knew lack of sleep is a primary trigger for mania" (p. 236). Vicky stated that, at times during her depression, she felt like she could not cope and did not want to look after John any more.

Vicky stated that, she had conflicting emotions associated with John's ASD. At times, she felt happy for the diagnosis, whilst, at other times,she was greatly distressed by the impact in terms of her relationship with John and other family members. She noted that caring for John inhered a significant emotional burden. 
Vicky also articulated that she had felt, and continued to feel, to a certain degree, a sense of bitterness in terms of the life-normality she perceived herself to have lost, such as a "normal" (i.e. emotionally communicative and mutually understanding) relationship with her child. She stated: "so I feel really, really bitter against no one, because there's no one to blame but all my life I'm grieving the child I haven't had." Sarah also felt that her life would have been very different if she had not had a child with ASD. However, she argued that she accepted what "God had done, but wished for something good to come out of it..." It was evident that the emotional pressure of looking after a child with ASD had impacted upon both Vicky and Sarah'sperspectives of their relationships with their sons. Vicky appeared to be looking for someone to blame for John's ASD. Although she acknowledged that no one could be blamed, she still expressed bitterness regarding how difficult life with John had been. Conversely, Sarah's spiritual convictions meant that she attributed responsibility to God, even though she also wished for an alternative arrangement. Wilson and Wilson's publication, entitled The Life You Never Expected, addresses how, in such cases, attributing responsibility to God can allow the parents of children with ASD to both manage and rationalise the stress of daily life:

\begin{abstract}
“Special needs ... we didn't plan for them, and we didn't anticipate them. Because our children are such a beautiful gift, we often feel guilty for even saying this, but we might as well admit that we didn't want our children to have autism, any more than we wanted them to have Down's Syndrome, or cerebral palsy, or whatever else." $\quad$ (Wilson and Wilson, 2015, p. 36).
\end{abstract}

Vicky also appeared to possess an internalised iamge of what life "should" be like as a parent - John had challenged such perceptions. Raising John had strained the nature of her family relationships. Having a child with ASD affects the whole family, specifically the parents, as they worry about fulfilling their responsibilities, their child's future, and about the impact of the child's behaviour on other family members (Tissot, 2009). Vicky disclosed that having a son with ASD had placed a significant amount of pressure upon her husband, Philip. Vicky explained that she had used work as a coping mechanism and as a means to escaping her family commitments:

"I just wouldn't want to come home sometimes and therefore would stay at work... to avoid being at home and Philip having to care for John. This would place a burden on our marriage and he would argue and blame me when I got in for deliberately coming home late. Home wasn't relaxing anymore."

Thus, she would spend many hours working late at school, and took on various additional managerial responsibilities, in her attempt to avoid confronting the issues within her life. As a result, the time she spent with John and Philip was reduced and when seeing them, was at the close of a busy day when all they were tired, and sometimes irritable. This, however, placed further pressure upon Philip to look after John. Philip, who worked, as well as looking after 
John, struggled to do so without Vicky around. The guilt of not wanting to spend time at home - guilty for avoiding what she saw as her responsibility - but felt the lack of emotional strength to return home to John and Philip. Stillman (2008) argues that guilt is often associated with giving birth to, and parenting children with autism due to a multi-faceted number of issues around the condition. Vicky's guilt thereof, as well as the extent to which she avoided spending time at home, caused arguments between her and Philip regarding the distribution of John's care. The practical and emotional pressure upon both parents meant that their marriage was strained to breaking point. Robledo and Ham-Kucharski (2005) state: "my marriage has suffered from the challenges of raising an autistic child" (p. 101). Eventually, Philip decided to leave Vicky and John, living seperately from them and maintaing contact and visiting at weekends. Similarly, Sarah also explained that looking after Max had been tough on and both her and her partner and that, as a result, many arguments had occurred and their relationship had been "strained" at times. Although Sarah had not separated from her partner (as with Vicky), she did acknowledge the emotional impact that raising Max had effected upon both herself and her partner, as well as their relationship.

Although Philip still engaged in regular contact with Vicky and John, he did not look after John as much as Vicky. This had, according to Vicky, created further difficulties, as she was now both a primary carer and a full-time school teacher. Vicky explained that she found it almost impossible to find time for herself during this period. In contrast, Sarah was closely supported by her family, who helped her and provided respite care for Max, allowing her time to herself. She stated that sometimes she felt like running away from all her responsibilities:

"Sometimes I just wanted to get away and never come back ... or at least, come back after a long rest ... I'm just exhausted and am always so worn out - the care of someone with ASD is wearing."

It was clear that Vicky's health had suffered significantly, with bouts of depressive illness and suicidal ideations. Vicky described her life (at times) in terms of a nightmare with no end, stating that if she could see a brighter perspective or future,she might discover a glimmer of hope therein. She noted:

"All this impacted my life, my family, my marriage and my mental health - at times there seemed no answer and I became very down. Seeing no way out or prospect of anything better occurring made me ill, and ruminating on it was worse."

Tilton (2010) describes this type of feeling as "the loss of dreams" (p. 20). In this loss,Vicky felt as though she had become trapped and had no way out of her life-situation. However, Vicky also remarked about the positive nature of John's school, how the school had had helped him, and how this had provided her with a little more peace of mind, which was something she held onto when she felt helpless. Hochschild (1983) argues that challenging feeling rules can help individuals, in this case, allowing Vicky to grieve, without feeling guilty about it 
- this may assist her in the production of a more positive outlook and help secure enhanced holistic wellbeing.

Finally, Vicky noted that the long-term mental health impact of caring for John could be hard to measure or even comprehend but suggested happiness would increase as John became more autonomous. Vicky clearly wanted John to develop his talents and not be dependent upon her as an adult. She also did not desire her mental health to be adversely impacted and potentially 'damaged' by her having to continually care for John into adulthood. This would create further pressure for her, especially as she would be unable to perceive of a point in time when John might gain (and be capable of) independence. Vicky questioned whether or not John would be able to drive, sustain relationships, have a job or be happy. Tissot's (2009) research suggests that autistic people may experience difficulty in comprehending the limitations of socially acceptable sexual behaviour, especially in terms of ensuring privacy, when for example masturbating, which can have ramifications in terms of limiting the formation of friendships and relationships. Vicky wanted John to be happy, to understand social "norms," and find his place in society as a "success." Vicky felt that John was better at attaining practical skills than at academic learning, and thought he might be suited to this type of work in later life. However, she did question whether he could be employed, as this would mean communicating with others and understanding the behavioural dynamics of the workplace. Robledo and Ham-Kucharski (2005) suggest that "it is possible that your child will be gainfully employed as an adult ..." (p. 138). Equally, individuals with SEN can be aided in their search for employment by college support programmes. However, although such sentiments may be of solace to those anxious, there are no guarantees of such success. For example, Jordan (2013) argues that employment may not be a viable option for people with ASD and that few, if any, individuals with autism will be able to function without the provision of significant support. Vicky stated that if John was unable to "make it in the world" and established some level of independence, he could suffer from anxiety, isolation, loneliness and be the subject of misunderstanding. Vicky underlined that, specifically in terms of relating to and engaging with others, John's social and emotional difficulties isolated him. Clements and Zarkowska (2000) note that "many people with autism are socially isolated... Some clearly describe their feelings of loneliness" (p. 114). She was also concerned that her susceptibility to mental illness would "rub off" on John, especially if (in later life) he was unable to find unemployment, communicate with people, and foster / maintain relationships. Tilton (2010) argues:

"Depression may occur in children with ASD, especially in older children with Asperger's, due to the sense of isolation and frustration that accompanies their social and emotional issues. Depression may also occur after a severe injury or shock, or due to an underlying genetic or metabolic condition." (Tilton, 2010, p. 135). 


\section{Conclusion}

Identifying the emotional work of providing for the needs of, and living with children with ASD, this study has examined how, in a family environment, ASD impacts upon the psychological wellbeing of both the parents (as carers) and the affected child. It is evident that Hochschild's (1983) 'emotional work' played out in both participants lives. The interview data highlighted that Vicky perceived the ASD specific needs of son as being too complex for the care system provided by some mainstream education settings. Sarah questioned sending Max to her local mainstream school for similar reasons, but had reservations about specialist schools. The main differences between the two systems were, in her view, the style of teaching and the specific teacher-training and experience specialist schools have in managing the needs of children with ASDs. It appeared that, during the time of this research, John's needs were being met at the specialist school.

The key findings in relation to this research were that both Sarah, and particularly Vicky, found the experience of having a son with ASD to be emotionally and psychologically exhausting. This sentiment was evident in Vicky's expression of grief regarding the perceived loss of a "normal" motherson relationship. Vicky also underlined how having a son with ASD had impacted upon her marriage, placing a significant strain upon her relationship with her husband, eventually contributing to her marital breakup. Equally, Sarah shared the emotional turbulance of caring for her son and the holistic problems this had caused, including domenstic relational difficulties.

Although not an isolated issue, there is still much to be learnt about ASDs. The personal or organational policy or interface can mean that for example, within any profession, inclusive of social work, individuals' knowledge of ASD can be superficial or limited by access to training opportunities (Preece and Jordan, 2006). Equally, Ferneaux and Roberts (2018) argue that the training of teachers in specifically working with children with ASD has not been rolled-out across the profession, and although courses exist, including Continuing Professional Development (CPD) and Postgraduate training, some educators are still uniformed about effective practice in this field.

How social workers, teachers and others perceive ASDs affects the extent to which communication (pertaining to matters thereof) occurs between the home and the school, and effective and empathetic services and interventions attending to the domestic needs of the ASD affected child and their family are provided. A greater awareness and appreciation of ASD would be beneficial in terms of ensuring the provision for sufficiently adequate care and the fostering of positive relationships with children who are on the autistic spectrum (Higashida, 2017). Johnson and Rensselaer (2010) argue that "accepting their autism helps you to move on and you can start to see the person they are" (p. $52)$. 


\section{Key Recommendations}

Hochschild (1983) noted the 'emotional work' - unpaid - in contrast to labour, for which a wage is given in looking after another, supressing feelings and ensuring, for example a household runs efficiently. However, the recommendations to limit the 'emotional work' of carers is to aim to create strategies and implement differentiated, tailored provision for the needs of those with ASD. The promotion and advance of pedagogically-informed practice should be accompanied by research-led and informed practice. This research has therefore highlighted a number of issues germane to the assiduous task of parenting of a child with ASD, in particular, awareness of the stress this type of around-the-clock care can create.

A first recommenadtion is, the need for scheduled breaks, away from the emotional impact of care, is a necessary. This has the potential to allow the primary carer the opportunity to step away from the needs of an individual and take time to recover from the emotional work associted with parenting. Under the current system of welfare support, the government universal credit system would need to take greater account of the needs of carers. This provision would need to be managed effectively and be a sustained period of time, rather than a few hours, to allow carers the opportunity to rest for a period of time, from the stress of care (Dabrowska and Pisula, 2010). Although sometimes 'breathing sapce' (Schopler and Mesibov, 2013, p. 127) is created, a drive towards increasing the level of support for carers appears invaluable to promoting effective health and wellbeing, as well as supprting the needs of the wider family and siblings.

Second, awareness of strategies to support parents and a range of practitioners facilitate effective intervention and support for managing aspects of the triad of difficulties, is a common feature arising from this study; staff, in some of the mainstream schools were unaware of how to effectively meet the needs of the children in this study. This may be specifically targetted at managing the 'emotional regulation' (Blome, 2018, p. 10) of a calm state, optimal arousel for effective learning to occur. Moreover, appropriate stimulation, rather than overstimulation of sensory experiences, which may lead to overload, need to be promoted (Bogdashina, 2016). This could include painting, feely bags, aromotherpy, aimed at the development of tactility (perception of touch) and olfaction (perception of odours / scents) activities and excerises to help dexterity and the position of the body in relation to other items - proprioception. In the classroom, the creation of a work zone, clutter free, allowing the individual opportunity to access materials in a personalised way, adapted for their needs. Equally, educators should be aware of the impact of noise, seeking to reduce volume in the classroom (conceivably allowing headphones or sound mufflers to be worn). In addition, creating predictability of routines, avoiding, where possible, unexpected change (and consider the creation of planned picture routine cards) to assist in working through social-communicative difficulties through social skills groups and role-play / drama (Boroson, 2016). 
In terms of social work practice, it would be of substantial advantage if practitioners were cognisant of the salient issues referenced in this research, as a distinctive overlap between education and social work exists. This includes the need for understanding a person's needs within, for example, the conceptual framework of a systems theory, rather than seeing needs thereof as existing within a contextual vacuum, is fundamental to effectiveness of any form of social work, from the initial diagnoses, through the implementation of care interventions, to any subsequent reviews of practice (Pycroft and Bartollas, 2014). In practice, from initial assessment - forming life accounts, creating genograms, assessing risk and harm - to forming action plans and reviewing them, social workers will have contact with individuals with ASD. A systems theory approach observes and analyses the impact of a range of contributory factors upon behaviour, welfare and interactions (Greene, 2017). Investigating phenomena from a holistic stance could help understand how, when, for example, the boys cited in this work, behaved as they did, a systems approach could analyse the triad and look for triggers. Equally, understanding the needs of the carers, from a systems schema, helps develop an understanding of their behaviour towards their children and look for ways of managing meltdowns / extremities of behaviour. Consequently, when creating an initial assessment or forming background information, such as the devlopment of Pathway Plans, it would be efficacious if the social worker sought to understand the impact of ASD upon the individual and their family. Consciousness of the symptoms of ASD and how these impact upon the family life of those involved in their care, is likely to produce a much more understanding and empathetic social or health care worker. This awareness of the complexivity of needs of these vulnerable young people, and the needs of their carers, puts social workers in a stronger position to help facilitate tailored care packages of support for young people and their families. Gould (2016) argues that social workers play a role within multidiciplinary teams in advocacy, support and education in helping parents establish behaviour techniques to manage their child's behaviour, establish entitlement and access provision.

Beckett and Horner (2016) argue the nature of contemporary social work is broad, encompassing a range of organisations and activities and drawing upon a range of disciplines theories. Thus, innovative practice, underpinned by theory and faciliated by positive relationship-based practice between those involved in eduaction and health care planning and delivery, will undoubtably, help liasion with parents in supporting them in the management of their emotions and needs, whilst providing support for the child, assisting in efficacy and outcomes. This is because, on a daily basis, social workers need to engage with and assist distressed individuals (Ruch and Turney, 2018). Knowing how to relate to young people and develop meaningful connections can be challenging within overly-bureaucratised frameworks (Broadhurst et al., 2010). Although a growing-knowledge base is emerging from a social-pedeagogical work, the limits of practitioner understanding to how to cater for the functional and emotional needs of those involved involved in the care of ASD. 
In summary, due to the nebulous nature of ASD, the varstness of the scope of social work practice, and the limited extent to which research has been conducted regarding the emotional work inherent to parenting children with ASD, this work has sought to provide an enhanced clarity of issues relating to the, sometimes subjective, practises employed when providing ASD-based care. This research has highlighted the significant need of further research to develop and inform practice across disciplines.

\section{Appraisal of research and further lines of enquiry}

This work draws upon Hochschild (1983) and offers original percipinet into the emotional impact of those involved in the care of those with ASD. It has highlighted the need for enhanced training, developed awareness acrosss professions and further research. As ASD is recognised within a comorbidity of conditions (Richards and O'Hara, 2014), a perspicacious project exists, beyond the scope of this work, but is a needful avenue for further resarch in the field. As an appraisal of the research methodology employed; historically, the study of biography in sociological enquiry been under-developed, some of the early pioneers of sociology biography, including Wilhelm Dilthey, did have not had their work significantly advanced. However, with the development of Paul Ricoeur's work on interpretation, narrativity, chronology and the hermeneutics of biography, this type of research has been established. In more recent literature, Norman Denzin (Denzin, 1989) wrote about interpretative lifeaccounts and Michael Erben (Erben, 1998) who suggested the importance of imagination in interpreting narrative. To exemplify, thus, creating a 'story' of a life lived on a trajectory, marrying theoretical sentiments with empirical data. It has been the intention of this work to use interview schedule data to build upon a punctilious narrative, allowing a platform for Vicky and Sarah's life stories, which is aimed at informing and advancing awareness of the orbed issues this research has sought to explore.

\section{References}

Atkinson, D. (1998). An autobiographical approach to learning disability research Aldershot: Ashgate.

Attwood, T. (2007). The complete guide to Asperger's syndrome. London: Jessica Kingsley.

Barbalet, J. M. (2001). Emotion, social theory, and social structure: A macrosociological approach. Cambridge: Cambridge University Press.

Baron-Cohen, S. (1995). Autism. The facts. Oxford: Oxford University Press.

Baron-Cohen, S. (2008). Autism and Asperger syndrome. Oxford: Oxford University Press.

Beckett, C., \& Horner, N. (2016). Essential theory for social work practice. London: Sage.

Bierens, F. (2010). A spectrum of light: Inspirational interviews with families affected by autism. London: Jessica Kingsley.

Blome, L. (2018). Practical Strategies for Supporting Emotional Regulation in Students with autism. London: Jessica Kingsley. 
Bogdashina, O. (2016). Sensory Perceptual Issues in Autism and Asperger Syndrome. London: Jessica Kingsley.

Boroson, B. (2016). Autism Spectrum Disorder in the Inclusive Classroom. New York: Scholastic.

Bowler, D. M. (2008). Autism spectrum disorders: Psychological theory and research. Chichester: John Wiley \& Sons.

Boyd, B. (2004). Parenting a child with Asperger Syndrome: 200 tips and strategies. London: Jessica Kingsley.

Broadhurst, K., Hall, C., Wastell, D., White, S. and Pithouse, A. (2010) 'Risk, instrumentalism and the humane project in social work: Identifying the informal logics of risk management in children's statutory services', British Journal of Social Work, 40, pp. 352-70. doi.org/10.1093/bjsw/bcq011.

Carr, A., Lineham, C., O'Reilly, G., Walsh, P., McEvoy, J. (2016). The Handbook of Intellectual Disability and Clinical Psychology Practice. London: Routledge.

Cheney, T. (2008). Manic: A woman in pain, a life in chaos, the courage to fight a secret madness. London: HarperElement.

Clements, J \& Zarkowska, E. (2000). Behavioural Concerns and Autistic Spectrum Disorders. London: Jessica Kingsley.

Corbin, J. \& Strauss, A. (2015). Basics of Qualitative Research: Techniques and Procedures for Developing Grounded Theory. London: Sage.

Colvin, G. \& Sheehan, M. R. 2012. Managing the cycle of meltdowns for students with autism spectrum disorder. London: Sage.

Creswell, J. W., \& Creswell, J. D. (2018). Research Design. Thousand Oaks: Sage.

Dabrowska, A. \& Pisula, E. (2010). Parenting stress and coping styles in mothers and fathers of pre-school children with autism and Down syndrome. Journal of Intellectual Disability Research Volume: 54, Issue: 3, pp. 266 - 280. doi.org/10.1111/j.1365-2788.2010.01258.x

Denzin, N. K. (1989). Interpretive Biography. London: Sage.

Drew, K. \& Green, J. (2016). Refresh: Spiritual Nourishment for Parents of Children with Special Needs. Grand Rapids: Kregel.

Dubin, N. (2009). Asperger syndrome and anxiety: A guide to successful stress management. London: Jessica Kingsley.

Erben, M. (1998). Biography and Education: A reader. London: Falmer.

Ferneaux, B. \& Roberts, B. (2018). Autistic Children: Teaching, Community and Research Approaches. Oxford: Routledge.

Greene, R.R. (2017). Human Behaviour Theory and Social Work Practice. New Jersey: Transaction Publishers.

Gould, N. (2016). Mental Health in Social Work. Oxford: Routledge.

Guest, G., MacQueen, K.M.,\& Namey, E.E. (2012). Applied thematic analysis. London: Sage.

Hamlin, T. (2015). Autism and the stress effect: a 4-step lifestyle approach to transform your child's health, happiness and vitality. London: Jessica Kingsley.

Hawkes, H. (2013). Autism: A parent's Guide. Peterborough: Need To Know.

Higashida, N. (2017). Fall down seven times: Get up eight. A Young man's voice from the silence of autism. London: Hodder and Stoughton.

Hochschild, A. R. (1983). The managed heart: Commercialization of human feeling. London: University of California Press.

Hoopmann, K. (2015). The essential manual for Asperger syndrome (ASD) in the classroom: What every teacher needs to know. Philadelphia: Jessica Kingsley.

Johnson, J., \& Van Rensselaer, A. (2010). Siblings: The autism spectrum through our eyes. London: Jessica Kingsley.

Jones, G. (2002). Educational provision for children with Autism and Asperger Syndrome. London: David Fulton. 
Jordan, R. (2013). Autistic spectrum disorders: an introductory handbook for practitioners. Oxford: Fulton.

Kara, H. (2018). Research ethics in the real world. Bristol: Policy Press.

Karim, K., O'Reilly, M. \& Ali, A. (2014). A practical guide to mental health problems in children with autistic spectrum disorder: it's not just their autism! London: Jessica Kingsley.

Kanner, L. (1943). Child psychiatry. Oxford: Blackwell Scientific Publications.

Kidd, S. L. (2011). My child has autism, now what? 10 steps to get you started. London: Jessica Kingsley.

Letherby, G. \& Bywaters, P. (2007). Extending social research: application, implementation and publication. Maidenhead: McGraw-Hill/Open University Press.

Leaf, J. (2017). Handbook of social skills and Autism spectrum disorder: Assessment,curricula, and intervention. California: Springer.

Mackenzie, H. (2008). Reaching and teaching the child with autism spectrum disorder: using learning preferences and strengths. London: Jessica Kingsley.

Merriam, S.B. (2019). Qualitative Research in Practice: Examples for Discussion and Analysis. San Francisco: Jossey Bass.

Nettleton, M. \& Friel, J. (2017). Special Needs and Legal Entitlement, Second Edition: The essential guide to getting out of the maze. London: Jessica Kingsley.

Preece, D., \& Jordan, R. (2006). Social workers' understanding of Autistic spectrum disorders: an exploratory investigation. The British Journal of Social Work, 37(5), 925-936. doi.org/10.1093/bjsw/bcl089

Pycroft, A. \& Bartollas, C. (2014). Applying complexity theory: Whole systems approaches to criminal justice and social work. Bristol: Policy Press

Robledo, S., \& Ham-Kucharski, D. (2005). The Autism book. New York: Penguin group.

Roth, I., \& Barson, C. (2010). The Autism spectrum in the 21st century: Exploring psychology, biology and practice. London: Jessica Kingsley.

Ruch, G. \& Turney, D. (2018). Relationship-based Social Work. London: Jessica Kingsley.

Schopler, G.B., \& Mesibov, E. (2013). The Effects of Autism on the Family. New York: Springer.

Shacklock, G. \& Smyth, J. (2002). Being Reflexive in Critical and Social Educational Research. London: Routledge Falmer.

Stillman, W. (2008). The Soul of Autism. Franklin Lakes: New Page.

Tarbox, J., Dixon, D., Sturmey, P \& Matson, J. (2014). Handbook of Early Interventions for Autism Spectrum Disorders. London: Springer.

Tilton, A. J. (2010). The parent's guide to children with Autism: Practical and positive strategies to help you and your child cope with Autism. Newton Abbot: David \& Charles.

Tissot, C. (2009). Establishing a sexual identity: Case studies of learners with Autism and learning difficulties. Autism, 13(6), 551-566. doi.org/10.1177/1362361309338183

Wilson, A. \& Wilson, R. (2015). The life you never expected: Thriving while parenting special needs children. Nottingham: Intervarsity Press.

Wilson, J. (2010). Essentials of business research: A guide to doing your research project. Los Angeles: Sage.

Wing, L. (2003). The autistic spectrum: a guide for parents and professionals. London: Constable.

Yau, A. (2012). Autism. Marston Gate: Autism Sparks. 